\title{
SOCIAL COGNITIVE THEORY: THE RELATIONSHIP BETWEEN KNOWLEDGE, ENVIRONMENTAL OBSERVATION, OUTCOME EXPECTATION, SELF-EFFICACY, AND PREVENTIVE BEHAVIOR OF OVER WEIGHT IN ADOLESCENT
}

\author{
Edy Suyanto'), Mutalazimah²), Muhammad Akhyar3) \\ 1) Health Politechnics, Ministry of Health, Malang \\ 2) Muhammadiyah University at Surakarta \\ 3) Sebelas Maret University, Surakarta
}

\begin{abstract}
BACKGROUND: Obesity is a global health problem that has been increasing in various age groups, including adolescents. Overweight and obesity should be prevented to reduce the risks of various chronic diseases, including cardio-vascular diseases and diabetes mellitus. Albert Bandura proposed Social Cognitive Theory to explain health-related behaviors. This study aimed to determine the relationship between knowledge, environmental observation, outcome expectation, self-efficacy, and preventive behavior of overweight in adolescent, using Social Cognitive Theory.

SUBJECT AND METHODS: This was an analytic observational study with cross sectional design, conducted in Malang, East Java. A total of 90 overweight or obese high school students in Malang were selected for this study. A set of questionnaire was designed to measure knowledge, environmental observation, outcome expectation, self-efficacy, and preventive behavior of overweight. This questionnaire was tested for validity and reliability. The data was analyzed using multiple linear regression model on STATA program.
\end{abstract}

RESULTS: Environmental observation ( $\mathrm{b}=0.11$; CI $95 \%=0.00$ to 0.23 ; $\mathrm{p}=0.047$ ), outcome expectation ( $\mathrm{b}=0.11$; CI 95\% $=0.00$ to $0.22 ; \mathrm{p}=0.041$ ), and self-efficacy $(\mathrm{b}=0.14$; CI $95 \%=0.04$ to $0.24 ; \mathrm{p}=0.006)$ had positive relationship with preventive behavior of overweight. However, the relationship between knowledge and preventive behavior was not statistically significant $(b=-0.14 ; \mathrm{CI} 95 \%=-0.44$ to $0.15 ; \mathrm{p}=0.342)$. Together the independent variables in the model explained $38 \%$ of the variation in preventive behavior of overweight (adjusted $\mathrm{R}^{2}=38.06$ ).

CONCLUSION: Environmental observation, outcome expectation, and self-efficacy had positive relationship with preventive behavior overweight.

Keywords: knowledge, environmental observation, outcome expectations, self-efficacy, preventive behavior. 